\title{
RUNNING DESIGNS THAT AFFECT CALORIES BURNED
}

\author{
Zahayu Md Yusof, Masnita Misiran, Adyda Ibrahim \\ Universiti Utara Malaysia, Kedah, Malaysia \\ Jurnal Sains Sukan dan Pendidikan Jasmani 7(2): 110-120, Received: 15 October 2018, \\ Accepted: 25 November 2018
}

\begin{abstract}
Balanced between good diet and regular physical activity is among the important factors in avoiding unhealthy weight gain. Our objective in this study was to investigate the amount of calorie loss against a variety of running exercises. In this study, an experiment on running as a calorie burning physical activities was conducted. Two factors were selected, the distance, and the level of difficulties. The result and statistical analysis concluded that both factors play significant roles in burning calories, with distance as being the most significant factor. The findings also suggest that other than increasing the distance, choosing a hilly terrain when training can give more efficient calories burn. There is no interaction between distance and the level of difficulties. Individuals should plan their workout accordingly only after knowing how many calories they burned through each activity. For individual with aims to burn more calories, an increase in distance and a hilly terrain is more favorable.
\end{abstract}

Keywords: design of experiment, running, calories burning.

\section{INTRODUCTION}

Regular physical activity and a balanced and nutritious diet are among the essential factors in preventing unhealthy weight gain. Physical activity increases lean body mass, muscle, and bone strength, and promotes good physical health. Physically inactive people promote the increase risk of the world's major non-communicable diseases (NCDs) of coronary heart disease (Lee et al., 2012; Oldridge, 2008), depression and anxiety by $12 \%$, colon cancer by $31 \%$, heart disease, osteoporosis and stroke cases (Garret, Brasure, Schmitz, Schultz \& Huber, 2004) and obesity (Jakicic \& Rogers, 2013; Wolin et al., 2010). A work by Taylor \& Dorn (2006) also suggested the existence of correlation between physical inactivity and road traffic accidents.

The Centre for Disease Control and Prevention in the US has been promoting strategies to increase participation in physical activities among its local communities. These strategies include the engagement in community-wide campaigns, individually targeted programmes, school based 
physical education (PE), any intervention that provides social support for physical activity in community setting, and the interventions to provide people with greater access to places for physical activity. Macera (2010) suggested the reduction of television viewing time by involving in community based program and school based program for children and adolescents. Saris et al. (2003) advised that sedentary adults should spend at least 30 minutes or more of moderateintensity physical activities, preferably every day of the week. They provided guideline that the best physical activities of the ancestral human is 1000 kcald-1 with calories consumption of 3000 kcald-1, resulting to a ratio of 3:1, as opposed to the current sedentary human ratio of 7:1.

Realizing the importance of physical exercise, people are continually seeking physical activities. The simplest form of activities which require very few equipment and easy access are walking and running. Many studies have been done to attain efficient running activity with the simultaneous goal to maximize the caloric expenditure in their endurance workouts (Takata, Tanaka, Ma, Huang, Apduhan \& Shiratori, 2007; Zhao, 2010; Norman, 2004). Some factors that can influence calorie-burning process through running include the type of track, food intake (including nutritional supplements), and other factor such as gender (Carey, 2009). Research has shown that a person walking one meter on a horizontal plane would burn 0.55 gram-calories of energy, provided that certain conditions are controlled. However, there has been limited research conducted on the running surface and distance.

This article aims to design an experiment to investigate the loss of calories against a variety of running exercises. By identifying which type of running activities that is most likely to burn more calories, and how to improve its performance to boost the calories burned. The workout plan will be improved. In addition to these, the most favorable combination of running type that will improve calories burns will be proposed. However, due to some limitation, this work will only consider the types of surface (level of difficulty) and the distance (meter) as the two main factors in calories burned through running.

\section{METHODOLOGY}

\section{Choices of factors, levels, and ranges}

Experimental designs are widely used to analyze a process or system in which the input variables are changed to observe the output response. Likewise, the process of calorie burning can mimic the use of experiment strategy in order to identify which design of running activities that may contribute to the most calories burnt.

Among the lists of factors that can affect calories burned through running include time of day (morning vs. evening), amount of sleep the night before the running training, the meal taken the night before, stretching, time taken for the run, the speed of the runner, and the condition of the running surface. Due to the limitation in this study, two variables have been selected as design parameters: 
1. Difficulty level (Level 1 and Level 2),

2. Distance (200m and 400m).

Note that the difficulty level is defined as the variability in the surface of road, where level 1 refers to running on the track, and level 2 refers to running on a hill. Other factors that may affect the experiment have been classified as follows:

\section{Held-Constant Factors}

- Gender: All runners were female.

- Weight: Range between 56 to $75 \mathrm{~kg}$ with very small difference in the height of runners.

\section{Nuisance Factors}

- Training effect.

- State of health.

Table 1: Factors, levels and ranges of running.

\begin{tabular}{|c|c|c|c|c|c|}
\hline No. & Factors & Type & Precision & $\begin{array}{c}\text { Range } \\
\text { (Low) }\end{array}$ & $\begin{array}{c}\text { Range } \\
\text { (High) }\end{array}$ \\
\hline 1 & Difficulty level & Categorical & In increments of 1 & Level 1 & Level 2 \\
\hline 2 & Distance (meter) & Numerical & 1 meter & 200 & 400 \\
\hline
\end{tabular}

\section{Selection of Response}

Calorie burn has been selected as the response variable for the experiment. It is measured by observing the readings of the Nike sport watch, with each runner being provided the same watch. Table 2 summarizes the characteristics of the response variable.

Table 2: Characteristic of the response variable.

\begin{tabular}{|c|c|c|c|}
\hline $\begin{array}{c}\text { Response } \\
\text { variable }\end{array}$ & $\begin{array}{c}\text { Normal Operating } \\
\text { Level and Range } \\
\text { (calories) }\end{array}$ & $\begin{array}{c}\text { Measurement } \\
\text { precision and } \\
\text { accuracy }\end{array}$ & $\begin{array}{c}\text { Relationship of response } \\
\text { variable to objective }\end{array}$ \\
\hline Calories & $0-999$ & Least count of 1 & As high as possible \\
\hline
\end{tabular}

\section{Choice of experiment design}

In this study, we proposed to conduct a $2^{2}$ completely randomized block design. Different runners were conducted in a random order and each runner was blocked in order to reduce the variability that may affect the results. The choice of blocking is also attributed to eliminating the known and controllable factor, which is the diet. Thus, we can systematically eliminate its effect on the statistical comparisons between the treatments. The experiment was completely randomized to 
reduce the effects of unknown and uncontrollable factors. Hence, runners, each in one block, and two replicates were chosen for the design.

\section{Performing the experiment}

The experiment was conducted in the Recreational and Sport Centre in Universiti Utara Malaysia. Two individuals from the group were selected to perform the experiment. They were similar in weight, diet and lifestyle. This experiment was conducted in two replications, where each runner performed a run twice. As previously stated, the two factors being considered in this study that may affect calories burning are the level of difficulty and the distance measured in meter.

For the difficulty level factor, level 1 was conducted on track and level 2 was conducted in a hilly trail of Puncak Vista in university campus. For the distance factor, 200 meters and 400 meters were considered as lower range and higher range respectively. The experiment was conducted within seven weeks, where each replication was performed in a single day. The experiment was conducted in the evening to reduce the risk of uncontrollable weather factor. Evening time was selected to reduce the heat of the day. Each runner was provided with a specific watch that was able to count the amount of calories burnt while running. Runners took an interval break of an hour for each level. The experiment was conducted in blocks and all the runs in each block were randomized. All the runs in a particular block were performed on one single day. The experiment was spread over a period of seven weeks.

\section{Instrument}

The Nike sport band and Nike fuel band was used to count the burning of calories through the completion of the activities. The device is capable of tracing the intensity of the movement of a person wearing it.

\section{RESULTS}

Table 3 shows the result of the running activities experiment that was conducted at all level of factors. Eight respondents have undergone the experiment. All respondents need to run at two level of factors that include distance and level of difficulty. They have to run a 200 meter and 400 meter on track and on hilly terrain. The calories burned for each respondent then were recorded.

Table 3: The results of the running activities

\begin{tabular}{|c|c|c|c||c|c|c|c|}
\hline No. & $\begin{array}{c}\text { Road } \\
\text { surface }\end{array}$ & Distance & Calorie & No. & $\begin{array}{c}\text { Road } \\
\text { surface }\end{array}$ & Distance & Calorie \\
\hline 1 & track & 400 & 24 & 17 & track & 400 & 23 \\
\hline 2 & track & 200 & 10 & 18 & track & 200 & 12 \\
\hline 3 & hill & 400 & 65 & 19 & hill & 400 & 65 \\
\hline 4 & hill & 200 & 32 & 20 & hill & 200 & 32 \\
\hline 5 & track & 400 & 24 & 21 & track & 400 & 23 \\
\hline 6 & track & 200 & 12 & 22 & track & 200 & 12 \\
\hline
\end{tabular}




\begin{tabular}{|c|c|c|c|c|c|c|c|}
\hline 7 & hill & 400 & 65 & 23 & hill & 400 & 64 \\
\hline 8 & hill & 200 & 34 & 24 & hill & 200 & 32 \\
\hline 9 & track & 400 & 23 & 25 & track & 400 & 24 \\
\hline 10 & track & 200 & 11 & 26 & track & 200 & 12 \\
\hline 11 & hill & 400 & 67 & 27 & hill & 400 & 65 \\
\hline 12 & hill & 200 & 34 & 28 & hill & 200 & 31 \\
\hline 13 & track & 400 & 23 & 29 & track & 400 & 23 \\
\hline 14 & track & 200 & 11 & 30 & track & 200 & 12 \\
\hline 15 & hill & 400 & 64 & 31 & hill & 400 & 66 \\
\hline 16 & hill & 200 & 34 & 32 & hill & 200 & 34 \\
\hline
\end{tabular}

\section{Statistical Analysis}

Figure 1 shows the interaction plot for these two factors. This finding shows no interaction between the factors that was conducted in this experiment. Therefore, it clearly suggests that the effects of distance on the calorie burned are not the same at all levels of difficulty area.

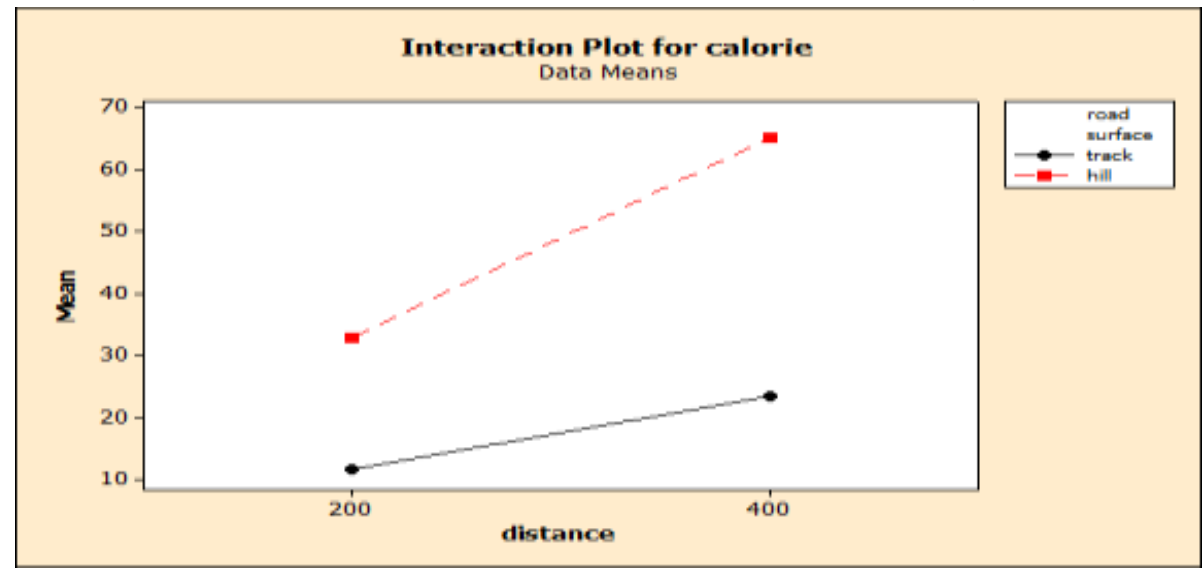

Figure 1: Interaction plot for calorie

Figure 2 shows the number of calories burned through different combinations of level and factors. The average values of calorie burned for all respondents that are recorded. The experiment suggests that the individual will lose 11.500 and 23.375 if they run on track with a distance of 200 meter and 400 meter, respectively. However, if they run on hilly terrain with a distance of 200 meter and 400 meter, the calories burned are 32.875 and 65.125 , respectively. 


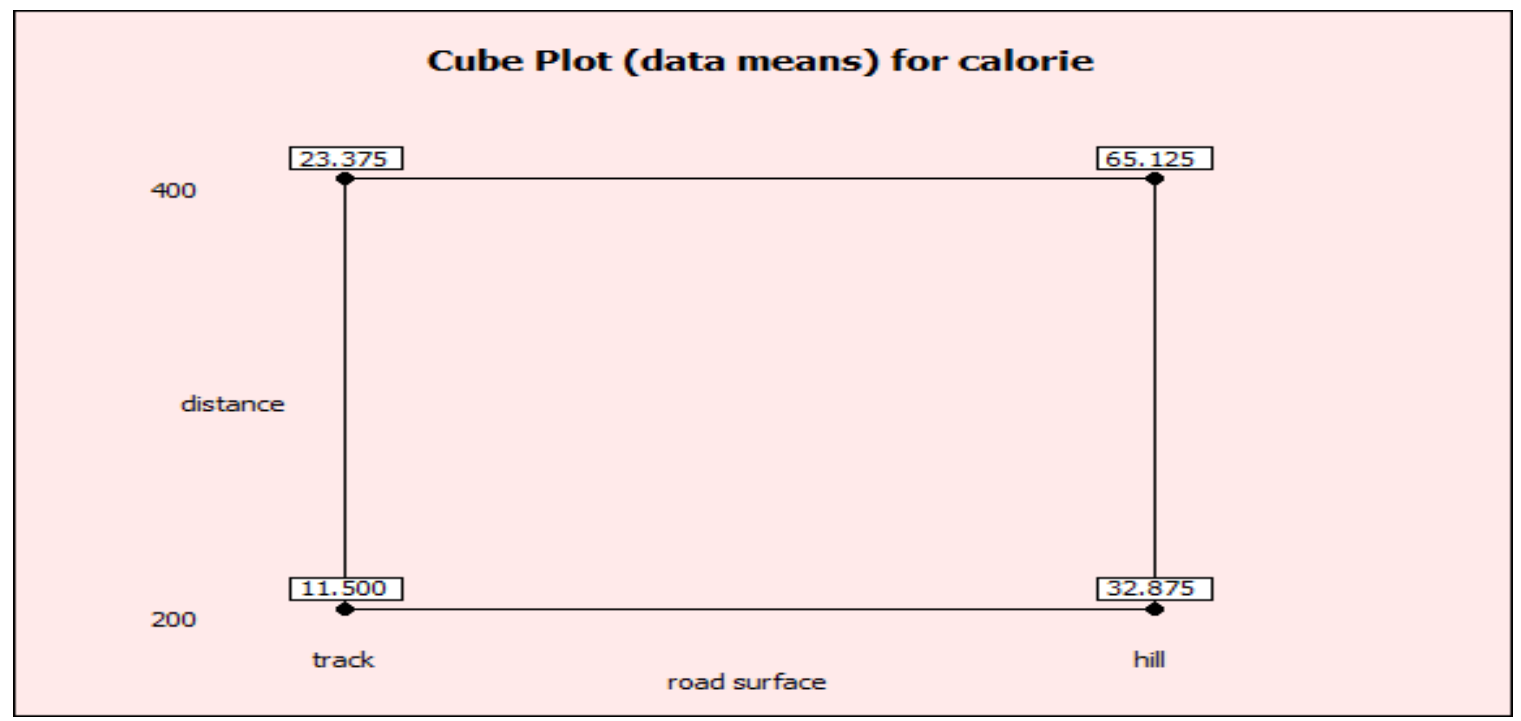

Figure 2: Cube plot for calorie

Figure 3 plotted the normal plot of the standardize effects; with exhibited factors A, B and $\mathrm{AB}$ have significant effect on the response. This finding suggested that the road surface, the distance and the combination of distance and road surface contributed to significant affect to the calorie burned.

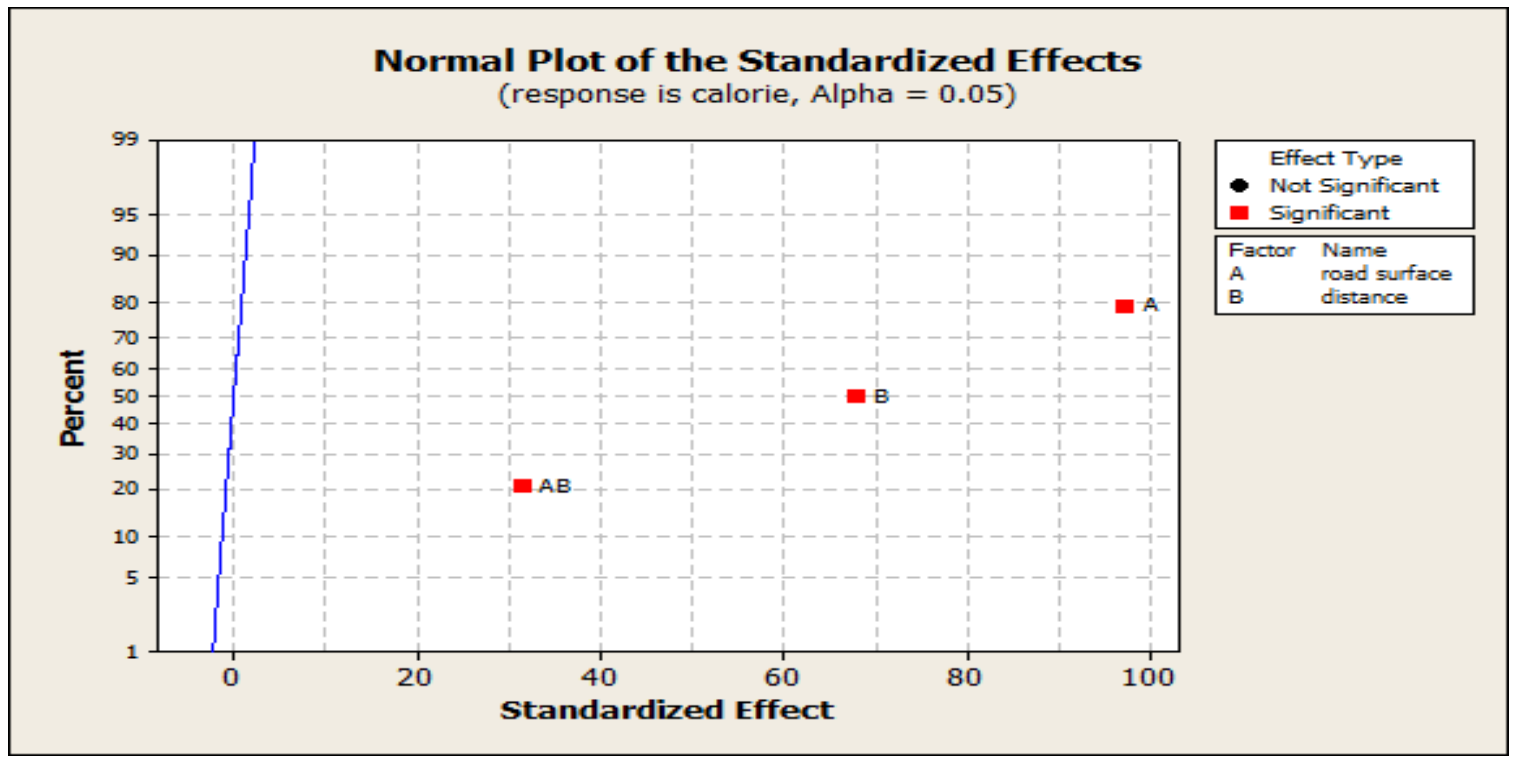

Figure 3: Normal plot of the Standardized Effects 


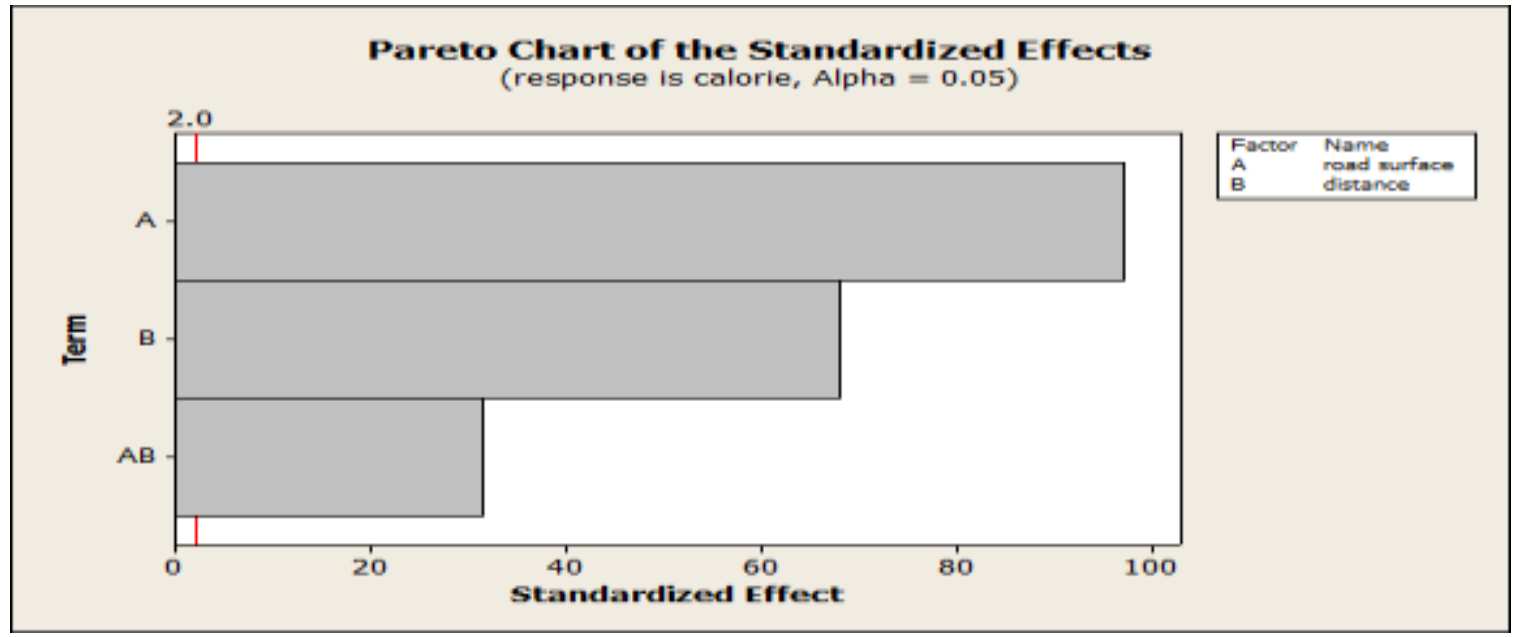

Figure 4: Pareto chart of the standardized effects

Figure 4 shows the Pareto chart of the standardized effects. Pareto charts shows which factors have statistically significant effects on the response at level 0.05 . Here we can see that factor $\mathrm{A}, \mathrm{B}$ and $\mathrm{AB}$ has significant effect for the response. Thus, the road surface, the distance and the combination of road surface and distance contributed significantly to the calorie burned.

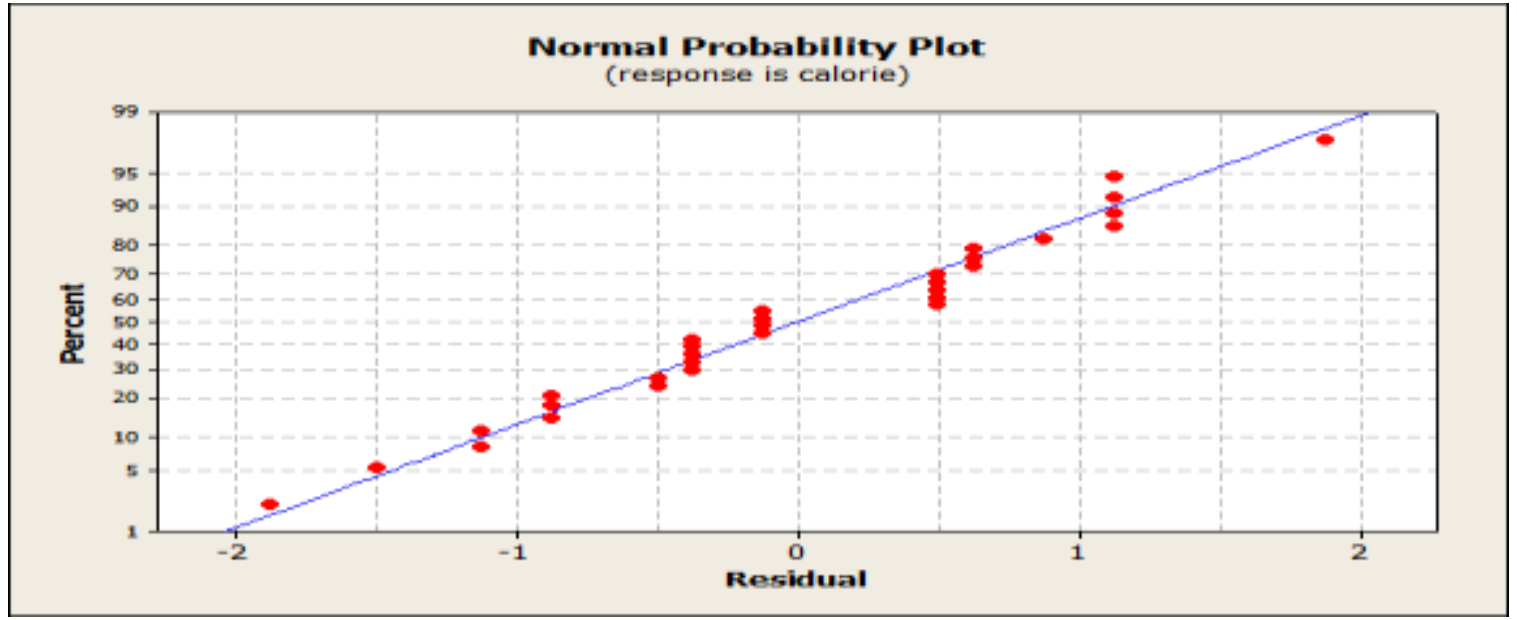

Figure 5: Normal probability plot

Figure 5 illustrates the normal probability plot of residual that is approximately linear, which support the condition that the error terms are normally distributed. The residuals in the normal probability plot followed a straight line, which indicated that they are normally distributed. 


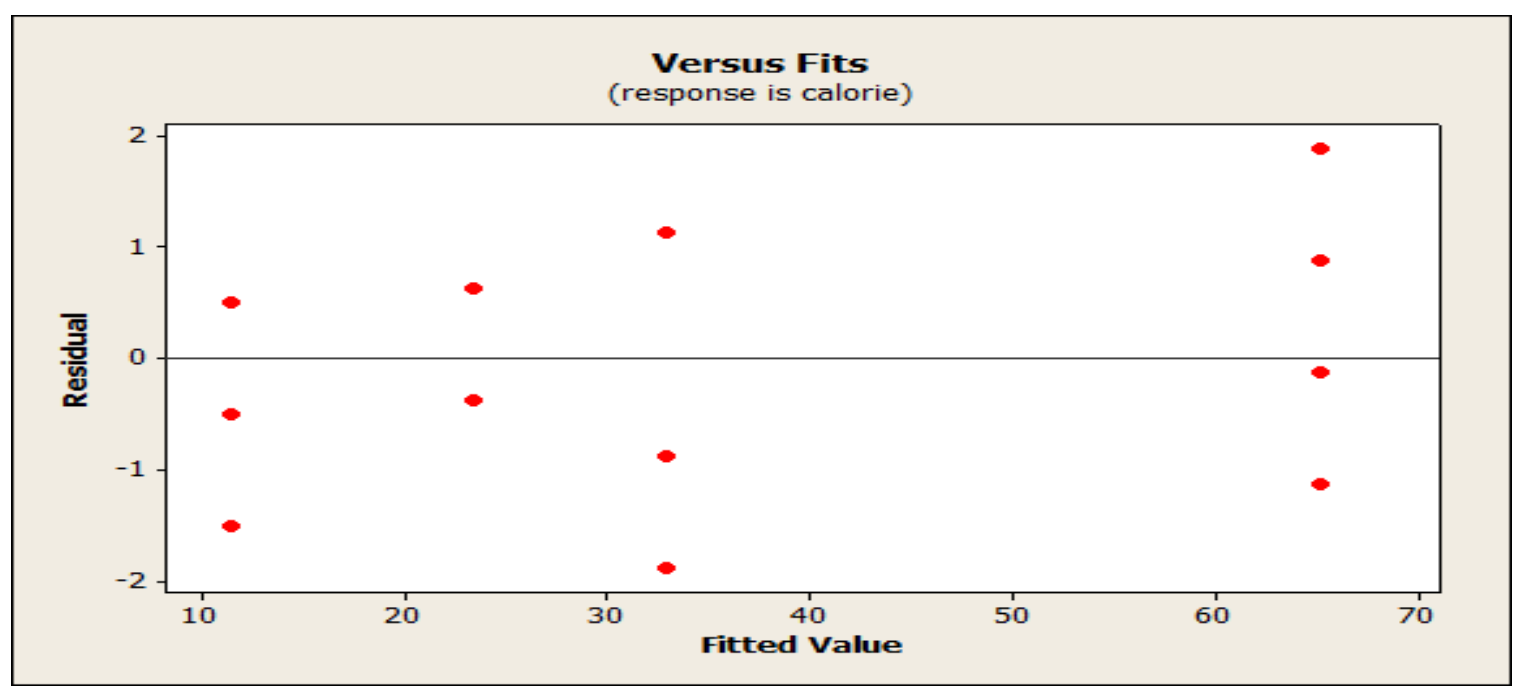

Figure 6: Versus fits

Figure 6 shows a graph of residuals versus the fitted values plot. The points on the plot above appear to be randomly scattered around zero, as to assume that the error terms have a mean of zero is reasonable. The vertical width of the scatter doesn't appear to increase or decrease across the fitted values, so we can assume that the variance in the error terms is constant.

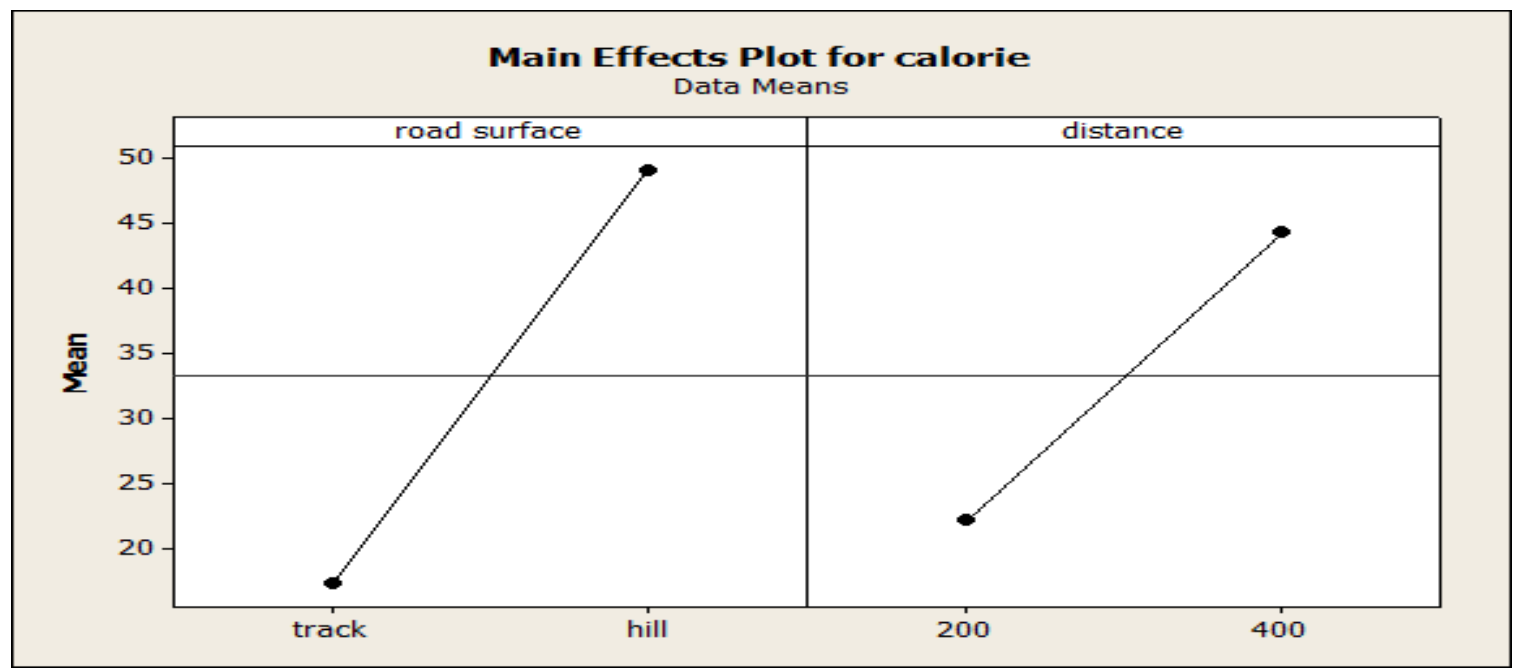

Figure 7: Main effects plot for calorie

Figure 7 shows that there is a strong relationship between the factors conducted in this experiment, which are distance (200 meter and 400 meter) and road surface (track and hilly terrain) with the calorie burned. Road surface affect the calories burned as the line is not horizontal. Hilly terrain produced higher effect on calories burned rate mean than on the track. Distance also affects the calories burned rate. A 400-meter had a higher calories burned rate mean than a 200-meter. The reference line represents the overall mean. 
Factorial Fit: calorie versus road surface, distance

Based from the output of estimated effects and coefficients for calories in Table 4, the predictor variables of road surface, distance and road surface*distance are all significant as the $p$-values of all variables are 0.000 that is lower than alpha level that is 0.05 .

Table 4: Estimated Effects and Coefficients for calorie (coded units)

\begin{tabular}{|c|c|c|c|c|c|}
\hline Term & Effect & Coefficient & $\begin{array}{c}\text { SE } \\
\text { Coefficient }\end{array}$ & T & P \\
\hline Constant & & 33.219 & 0.1624 & 204.57 & 0.000 \\
\hline Road surface & 31.562 & 15.781 & 0.1624 & 97.19 & 0.000 \\
\hline Distance & 22.062 & 11.031 & 0.1624 & 67.93 & 0.000 \\
\hline $\begin{array}{c}\text { Road } \\
\text { surface*Distance }\end{array}$ & 10.187 & 5.094 & 0.1624 & 31.37 & 0.000 \\
\hline
\end{tabular}

$\mathrm{S}=0.918559 \quad$ PRESS $=30.8571$

$\mathrm{R}-\mathrm{Sq}=99.81 \% \quad \mathrm{R}-\mathrm{Sq}(\mathrm{pred})=99.76 \% \quad \mathrm{R}-\mathrm{Sq}(\mathrm{adj})=99.79 \%$

The value of adjusted $R$-Squared is $99.79 \%$, meaning that a $99.79 \%$ of the variations in calories burned are explained by all predictors.

Table 5: Analysis of Variance for calorie (coded units)

\begin{tabular}{|c|c|c|c|c|c|c|}
\hline Source & DF & Seq SS & Adj SS & Adj MS & F & P \\
\hline Main Effects & 2 & 11863.6 & 11863.6 & 5931.78 & 7030.26 & 0.000 \\
\hline Road Surface & 1 & 7969.5 & 7969.5 & 7969.53 & 9445.37 & 0.000 \\
\hline Distance & 1 & 3894.0 & 3894.0 & 3894.03 & 4615.15 & 0.000 \\
\hline $\begin{array}{c}\text { 2-way } \\
\text { Interactions }\end{array}$ & 1 & 830.3 & 830.3 & 830.28 & 984.04 & 0.000 \\
\hline $\begin{array}{c}\text { Road } \\
\text { surface*distance }\end{array}$ & 1 & 830.3 & 830.3 & 830.28 & 984.04 & \\
\hline Residual Error & 28 & 23.6 & 23.6 & 0.84 & & \\
\hline Pure Error & 28 & 23.6 & 23.6 & 0.84 & & \\
\hline Total & 31 & 12717.5 & & & & \\
\hline
\end{tabular}

Table 5 shows that the main effects, road surface, distance and 2-way interactions are all significant because the $p$-values are 0.000 , which is lower than alpha value that is 0.05 .

\section{CONCLUSION AND RECOMMENDATION}

In this experiment, the result and the statistical analysis concluded that all factors involved are significant towards the investigated response with the most significant factors is distance. The finding also shows that the average number of calories burned through each activity. On average, subject that had run on track lost 11.5 calories if they run for 200 meter and lost 23.37 calories if 
they run for 400 meter. On hilly terrain, on average, subject lost 32.875 calories if they run for 200 meter and lost 65.12 calories if they run for 400 meter. We also find out that there is no interaction between the factors involve in this experiment, which are distance and the level of difficulties. Thus, it is recommended that individual should plan their workout accordingly only after knowing how many calories are burned through each activity. For individual with aims to burn more calories, an increase in distance and a hilly terrain is more favorable to burn more calories.

The finding also recommended future experiments to also include various level, i.e. a 200 meter, 400 meter, 600 meter with $2^{\wedge} 3$ factorial design. In addition, controlling nuisance factors i.e. diet, amount of sleep and rest also important factors to be considered. This is in relation to the uniqueness of each individual with unique metabolism rate, thus will affect calories burning. Other factors including speed, weight and running shoes should also be considered. A comparison of the number of calories burned versus individual body mass can also be considered in the future.

\section{REFERENCES}

Carey, D. G. (2009). Quantifying differences in the "fat burning" zone and the aerobic zone: implications for training. The Journal of Strength \& Conditioning Research, 23(7), 2090-2095.

Garrett, N. A., Brasure, M., Schmitz, K. H., Schultz, M. M., \& Huber, M. R. (2004). Physical inactivity: direct cost to a health plan. American journal of preventive medicine, 27(4), 304-309.

Jakicic, J. M., \& Rogers, R. J. (2013, June). The Importance of Physical Activity for Losing Weight, Maintaining Weight, and Preventing Weight Gain Brief. Research DIGEST, 14(2).

Lee, I. M., Shiroma, E. J., Lobelo, F., Puska, P., Blair, S. N., \& Katzmarzyk, P. T. (2012). Effect of physical inactivity on major non-communicable diseases worldwide: an analysis of burden of disease and life expectancy. The Lancet, 380(9838), 219-229.

Macera, C. A. (2010). Promoting healthy eating and physical activity for healthier nation.

Norman, J. M. (2004). Running uphill: energy needs and Naismith's Rule. Journal of the Operational Research Society, 55(3), 308-311.

Oldridge, N. B. (2008). Economic burden of physical inactivity: healthcare costs associated with cardiovascular disease. European Journal of Cardiovascular Prevention \& Rehabilitation, 15(2), 130-139.

Saris, W. H. M., Blair, S. N., van Baak, M. A., Eaton, S. B., Davies, P. S. W., Di Pietro, L., Wyatt, H. (2003). How much physical activity is enough to prevent unhealthy weight gain? Outcome of the IASO 1st Stock Conference and consensus statement. Obesity Reviews, 4(2), 101-114. doi:10.1046/j.1467789X.2003.00101.

Takata, K., Tanaka, M., Ma, J., Huang, R., Apduhan, B. O., \& Shiratori, N. (2007). A wearable system for outdoor running workout state recognition and course provision. In Autonomic and Trusted Computing (pp. 385-394). Springer Berlin Heidelberg.

Taylor, A. H., \& Dorn, L. (2006). Stress, fatigue, health, and risk of road traffic accidents among professional drivers: the contribution of physical inactivity. Annu. Rev. Public Health, 27, 371-391.

Wolin, K. Y., Luly, J., Sutcliffe, S., Andriole, G. L., \& Kibel, A. S. (2010). Risk of urinary incontinence following prostatectomy: the role of physical activity and obesity. The Journal of urology, 183(2), 629-633.

Zhao, N. (2010). Full-featured pedometer design realized with 3-Axis digital accelerometer. Analog Dialogue, 44(06).

¿- Zahayu Md Yusof

Universiti Utara Malaysia

Kedah, Malaysia

Email: zahayu@gmail.com 